\title{
Performance analysis of a new system for speed control in wind turbines
}

\author{
P. V. Silva, R. F. Pinheiro, A. O. Salazar and J. D. Fernandes \\ Universidade Federal do Rio Grande do Norte \\ Campus Universitário Lagoa Nova - Natal, 1524 Rio Grande do Norte (Brazil) \\ Phone/Fax number: +55 84 3215.3883, e-mail: paulo.silva@ifrn.edu.br, ricpinh@ufrnet.br, andres@dca.ufrn.br, \\ jefferson.fernades@ifrn.edu.br
}

\begin{abstract}
This paper presents a new system for speed control in wind turbines, the "Electromagnetic Frequency Regulator" (EFR). One of the most used devices in some topologies to perform the speed control are boxes of mechanical gears, plus a short shelf life, often represent sources of noise and defects. The EFR eliminates the use of these gearboxes, representing a technological breakthrough, making use of a machine adapted induction, where the then known stator of the machine becomes mobile, sympathetic to the turbine shaft. The aim of this study is to evaluate through simulations, efficiency in the speed control for wind variations and reference signals. Simulations showed good results, validating the proposed.
\end{abstract}

\section{Key words}

wind turbine, speed electromagnetic control, gearboxes, new technology.

\section{Introduction}

Rising demand for electricity is steadily increasing, contributing to the increase in environmental impact. It is necessary to invest in renewable energy. Among these sources, wind energy has taken great prominence by promoting the constant search for improvement of the technologies involved in the topologies of wind turbines, particularly in the issue of working with the variable wind speed, seeking a higher yield of the system [1].

According to the state of the art, wind turbines known as "variable speed" or "constant speed" are used. The first depend on electronics conversion systems to couple the turbine to the grid, which causes operational limitations when injecting energy produced into the grid, because of the voltage oscillations and quality of energy produced. In addition, both depend on the voltages of the mains, being disconnected when it ceases to operate due to a fault [2]. As examples of these types of wind turbines there are those who use Doubly-Fed Induction Generators (DFIG) and the multipole synchronous generators.

The constant speed wind turbines with greater reason require a mechanical system (speed multiplier) for compatibility with the speed of the turbine and the required to the generator connected to mains. As an example, we have the cage induction generator, described in [3]. In it, the stator is connected directly to the mains and, due to the low number of poles, a speed gearbox is required. This fixed speed is determined by the frequency of the mains and the load variation.

Analyzing the existing topologies, none provide the isolated operation and can be noted that one of the most important issues in the conversion of wind energy system for trans-formation of electric energy is the speed control [4]. It interferes directly in the frequency of the electricity generated, the power quality at the connection point between the park and the mains and the use of the kinetic energy of the wind turbine.

The speed multipliers, which seek to ensure your output synchronous speed required by the generator, involve very sophisticated technology and difficult access information, have shorter lifespan than other components of the wind turbine and often represent sources of noise and defects as explained in [5].

Due to this importance, several studies seek to increase the efficiency, lifetime and develop even more the technology of these multipliers. In one of these studies [6], the transmition gear is built as a dynamic multiplier, comprising a gearbox having a fixed ratio and a second gearbox with a hydrodynamic system. [7] analyze the effects of the traditional gear system, known as an epicyclic gear or planetary gear system. An-other technology, discussed in [8], working with a maximum power tracking algorithm at a variable electricity transmission system.

In the automotive field, there are related studies on Continuously Variable Transmissions (CVTs), which is able to continuously vary speed through an 'infinite' number of gear ratios [4].

The purpose of this paper is to contribute with a new speed controller for wind turbines and validate its effectiveness through simulations, developing a machine that resembles an induction machine and allows the system to work with variable wind speed, keeping constant the output speed of the proposed system, performing, for that, a speed control, dispensing the use of the traditional gearbox. For this purpose, a frequency inverter is connected to the machine, injecting currents to produce a rotating field armature, mainly responsible for speed control.

This paper has the following sequence: Section II will address the concepts of the proposed topology; in Section III aspects of modeling the aerodynamic model of the turbine and the proposed machine are presented; Section IV is presented the strategy used to the speed control and, 
in Section V, simulation results are presented. Finally, in Section VI, the conclusions are discussed.

\section{Description of the System}

Figure 1 illustrates the proposed system. The electromagnetic frequency regulator - EFR resembles an induction machine with a squirrel cage rotor, with three phase armature winding located in the part of machine known as the stator, since in a conventional machine this part is static. However, in this case, the armature winding rotates jointly with the axis of the wind turbine being named in this paper as asynchronous rotor, supported by bearings.

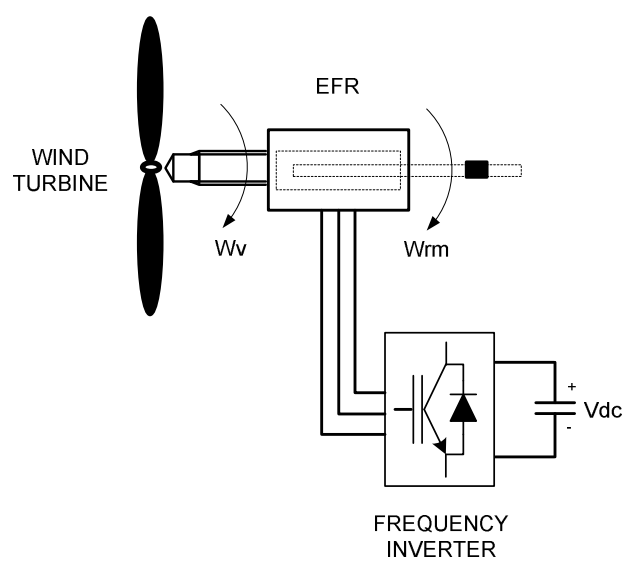

Fig. 1. Schematic diagram illustrating the proposed topology.

The armature winding of the asynchronous rotor is electrically powered via an frequency inverter that produces current at a frequency value which defines the speed of the rotating field, when adding the speed of the turbine $\left(\mathrm{w}_{\mathrm{v}}\right)$,results in a rotor speed $\left(\mathrm{w}_{\mathrm{rm}}\right)$, called synchronous rotor, at the desired synchronous speed value of the chosen generator axis, after deducting the value of the slip, as illustrated in the diagram of Figure 2, where the vectors of turbine speed $\left({ }^{W_{V}}\right)$, field speed of the asynchronous rotor $\left(\overline{W_{C_{-} R A S}^{F}}\right)$ and the final speed of the synchronous rotor $\left(\overline{W_{C_{-R S}^{F}}^{F}}\right)$ are related to the fixed reference axis and the speed of the rotating field of the asynchronous rotor current $\left(\overline{W_{C_{-} R S}^{R A}}\right)$, to the reference of the asynchronous rotor.

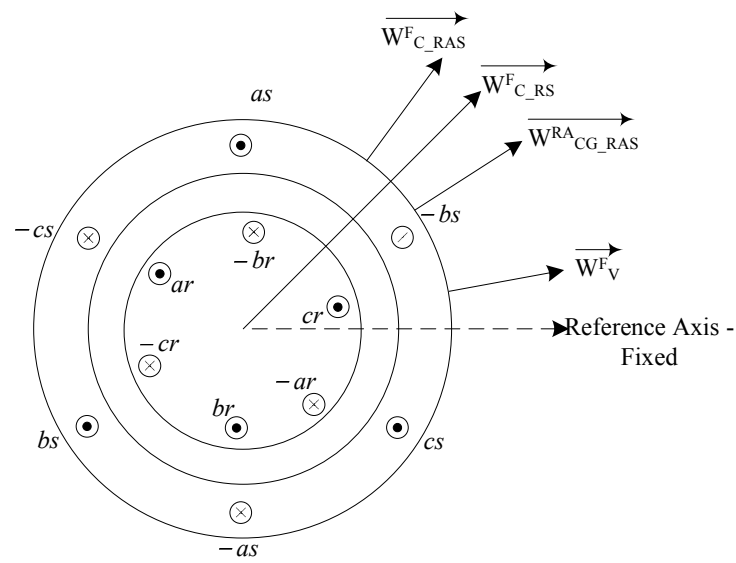

Fig. 2. Schematic diagram illustrating the proposed topology.

The reference system between the synchronous rotor and asynchronous rotor remains equivalent to a conventional induction machine, widely found in literature. However, the relative positioning between the synchronous rotor and the fixed reference axis becomes different from the conventional one, once the asynchronous rotor undergoes a displacement speed due to the turbine speed. Thus, it can be seen that the stationary fields between the asynchronous and synchronous rotor remains, essential condition for the maintainance of the electromagnetic torque that drives the synchronous rotor.

Analyzing the Equation 1, can be seen that for zero wind speed, is used the traditional system of reference, with the asynchronous rotor field vector equal to the rotating field vector of the injected currents, with that the rotor speed field equals to the synchronous rotor speed.

$$
\overrightarrow{W_{C_{-} R A S}^{F}}=\overrightarrow{W_{C G_{-} R A S}^{R A}}+\overrightarrow{W_{V}^{F}}
$$

The electric drive access to the armature of the adapted machine, or electromagnetic frequency regulator, occurs through brushes and collector rings.

The asynchronous rotor, contains the opening in which turns the squirrel cage rotor, separated from the armature by the air gap. Thus, the squirrel cage synchronous rotor rotates jointly with the chosen generator, at synchronous speed. With this, the EFR shall perform the function of speed control, replacing the currently known gearbox, constituting the electromagnetic frequency regulator.

The patent application prototype is under review at the INPI (National Institute of Industrial Property), with the register number: BR 1020140050590.

The fabrication of the prototype was started and the EFR parameters are presented in Tables I, those were used in the simulation fase. The physical structure of the prototype EFR is shown schematically in Figure 3. DC motor will perform the role of the wind turbine.

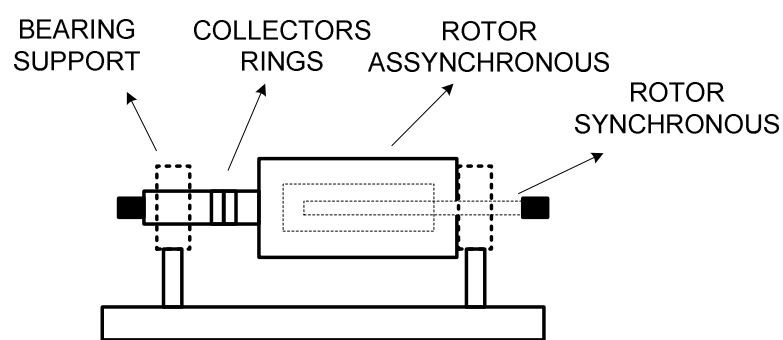

Fig. 3. Schematic diagram of the prototype - physical detail.

Table I. - EFR parameters

\begin{tabular}{|l|c|}
\hline \multicolumn{1}{|c|}{ Variable } & Value \\
\hline Power & $3 \mathrm{cv}$ \\
\hline Speed & $3400 \mathrm{rpm}$ \\
\hline Polo Pairs & 1 \\
\hline Resis/react. & $2,3 / 3,7 \Omega$ \\
\hline
\end{tabular}




\begin{tabular}{|l|c|}
\hline Resis/react. & $2,8 / 3,9 \Omega$ \\
\hline Mutual Inductance & $230 \mathrm{mH}$ \\
\hline
\end{tabular}

\section{System Modeling}

This section presents the turbine and EFR aerodynamic model.

\section{A. Aerodynamic Model Turbines}

The mechanical power of a wind turbine is obtained from the following equation [9]:

$$
T_{V}=\frac{\rho}{2} \pi R^{2} c_{P}(\lambda, \beta) v_{W}^{3}
$$

where $\rho$ is the air density, $R$ is the length of the propeller blades;

$c_{P}$ is the wind turbine power coefficient as a function of $\lambda$ e $\beta$, according to the equation:

$$
c_{P}(\lambda, \beta)=0,22\left(\frac{116}{\lambda_{i}}-0,4 \beta-5\right) e^{\frac{-12,5}{\lambda_{i}}}
$$

where $\lambda_{i}$ is obtained from:

$$
\frac{1}{\lambda_{i}}=\frac{1}{\lambda+0,08 \beta}-\frac{0,035}{\beta^{3}+1}
$$

and $\lambda$ is the ratio between the tips of the propeller blades linear speed and the wind speed being obtained by:

$$
\lambda=\frac{w_{v}}{v_{W}} \cdot R
$$

where $w_{v}$ is the angular speed of the turbine outlet, $\beta$ is the step angle of the blades and $v_{W}$ is the wind speed.

\section{B. $E F R$}

The voltages and flux armature of a conventional balanced three-phase induction machine can be represented in $\alpha \beta$ components (Clark Transformation) with the reference on the stator by the following equations [10]:

$$
\begin{aligned}
& u_{S \alpha}=R_{S} i_{S \alpha}+\frac{d}{d t} \psi_{S \alpha} \\
& u_{S \beta}=R_{S} i_{S \beta}+\frac{d}{d t} \psi_{S \beta} \\
& \psi_{S \alpha}=L_{S} i_{S \alpha}+L_{m} i_{R \alpha} \\
& \psi_{S \beta}=L_{S} i_{S \beta}+L_{m} i_{R \beta}
\end{aligned}
$$

For the rotor, also in $\alpha \beta$ components:

$$
\begin{gathered}
u_{R \alpha}=0=R_{R} i_{R \alpha}+\frac{d}{d t} \psi_{R \alpha}+\omega_{r} \psi_{R \alpha} \\
u_{R \beta}=0=R_{R} i_{R \beta}+\frac{d}{d t} \psi_{R \beta}+\omega_{r} \psi_{R \beta} \\
\psi_{R \alpha}=L_{R} i_{R \alpha}+L_{m} i_{S \alpha} \\
\psi_{R \beta}=L_{R} i_{R \beta}+L_{m} i_{S \beta}
\end{gathered}
$$

In (6) - (9), $R_{S}, R_{R}, L_{S}$ and $L_{R}$ are respectively the resistance and inductance of the stator and the rotor, and $L_{m}$ is the mutual inductance; $u_{S \alpha}, u_{S \beta}, u_{R \alpha}, u_{R \beta}, i_{S \alpha}, i_{S \beta}, i_{R \alpha}, i_{R \beta}, \psi_{S \alpha}, \psi_{S \beta}, \psi_{R \alpha}$ and $\psi_{R \beta}$ are $\alpha \beta$ components of voltages, current and flux in the stator and rotor, respectively;

$w_{r}$ is the rotational speed of the rotor.

Using Park Transformation voltages and flux on the stator are obtained for the biphasic system with rotating dq axes, on the stator reference:

$$
\begin{gathered}
u_{S d}=R_{S} i_{S d}+\frac{d}{d t} \psi_{S d}-\omega_{S} \psi_{S q} \\
u_{S q}=R_{S} i_{S q}+\frac{d}{d t} \psi_{S q}+\omega_{S} \psi_{S d} \\
\psi_{S d}=L_{S} i_{S d}+L_{m} i_{R d} \\
\psi_{S q}=L_{S} i_{S q}+L_{m} i_{R q}
\end{gathered}
$$

and the voltages and flux in the rotor to the biphasic system with rotating dq axes:

$$
\begin{gathered}
u_{R d}=0=R_{R} i_{R d}+\frac{d}{d t} \psi_{R d}-\left(\omega_{S}-\omega_{r}\right) \psi_{R q} \\
u_{R q}=0=R_{R} i_{R q}+\frac{d}{d t} \psi_{R q}+\left(\omega_{S}-\omega_{r}\right) \psi_{R d} \\
\psi_{R d}=L_{R} i_{R d}+L_{m} i_{S d} \\
\psi_{R q}=L_{R} i_{R q}+L_{m} i_{S q}
\end{gathered}
$$

where in (10)-(13), ${ }_{S d}, u_{S q}, u_{R d}, u_{R q}, i_{S d}, i_{S q}, i_{R d}, i_{R q}, \psi_{S d}, \psi_{S q}, \psi_{R d}$, and $\psi_{R q}$ dq are the voltages, currents and flux components in the stator and rotor, respectively;

$w_{S}$ is the rotational speed of the rotating field of the stator currents injected.

The electromagnetic torque produced in a conventional induction machine can be defined by:

$$
T_{i m}=p\left(\psi_{S d} i_{S q}-\psi_{S q} i_{S d}\right)
$$

where $\mathrm{p}$ is the pole pair number.

With this, the main equation of the overall energy balance of the system is defined by:

$$
H \frac{2}{P} \frac{d\left(w_{r}\right)}{d t}+J w_{r}=T_{E F R}-T_{e}
$$

where $H$ represents the moment of inertia of the overall assembly, $P$ is the number of pole, $J$ represents the frictional component of the overall assembly, $T_{E F R}$ is the output torque of the ERF and $T_{e}$ is the resulting electrical torque of the generator chosen connected to the axis.

The mechanical output torque EFR is given by the sum of the electromagnetic torque produced by the adapted induction machine to the torque produced by the turbine, defined by:

$$
T_{E F R}=T_{V}+T_{i m}
$$




\section{Control Strategy}

The type sizes to be used for the different parts in the paper are shown in Table I.

In this work was used the vector control method. This method decomposes the stator current in two vectors: one that produces the magnetizing flux and another that produces the torque, regulating them separately [11]. This control allows to achieve a high degree of accuracy and speed in the torque and speed control.

Among the techniques of vector control for asynchronous machines found in the literature [12], the control technique used was the quadrature control with the rotor flux reference.

Using (12) and (13) can be written the following dynamic equation for a generic framework, indicated by the superscript "g", relating the rotor flux and stator current:

$$
\frac{L_{m} \cdot R_{R}}{L_{R}} \cdot i_{s}^{g}=\frac{\psi_{r}^{g} \cdot R_{r}}{L_{R}}+\frac{d \psi_{r}^{g}}{d t}+\left(w_{g}-w_{r}\right) \psi_{r}^{g}
$$

Whereas in the rotor flux reference frame, from (17) and considering that: $\psi_{r d}^{r}=\psi_{r}, \psi_{r q}^{r}=0$ and $w_{s}=w_{r}$, has the model of the stator currents as a function of the rotor flux in the rotor flux reference expressed by the following equations:

$$
\begin{gathered}
\frac{L_{m} \cdot R_{R}}{L_{R}} \cdot i_{s d}^{r}=\frac{\psi_{r} \cdot R_{r}}{L_{R}}+\frac{d \psi_{r}}{d t} \\
\frac{L_{m} \cdot R_{R}}{L_{r}} \cdot i_{s q}^{r}=w_{r} \psi_{r}
\end{gathered}
$$

With this, the electromagnetic torque prior defined by (14), becomes simplified and defined by the following equation:

$$
T_{i m}=\frac{P L_{m}}{L_{R}} \psi_{r} i_{s q}^{r}
$$

where $i_{s d}^{r}$ and $i_{s q}^{r}$ are the stator reference currents in the rotor flux reference.

From (20) may be observed that the electromagnetic torque can be controlled by $i_{s q}^{r}$ and, by (18), the rotor flux can be controlled by $i_{s d}^{r}$, irrespective of $i_{s q}^{r}$, characterized decoupling control flow $\mathrm{x}$ conjugate.

The purpose of the speed control system is to keep the speed constant synchronous rotor and a value of $377 \mathrm{rad} /$ $\mathrm{s}$, the velocity reference.

The Figure 4 shows the block diagram for the control strategy of the system. The electromagnetic torque reference $\left(T_{e}^{*}\right)$ is calculated from a PI controller, the resulting error signal between the reference speed and the synchronous speed of rotation of rotor.

From the readings of current and voltage signals of the asynchronous rotor, is calculated the rotor flux and the angle reference which will be used to calculate the reference currents. PI controllers were also used for the reference signals of the PWM converter.

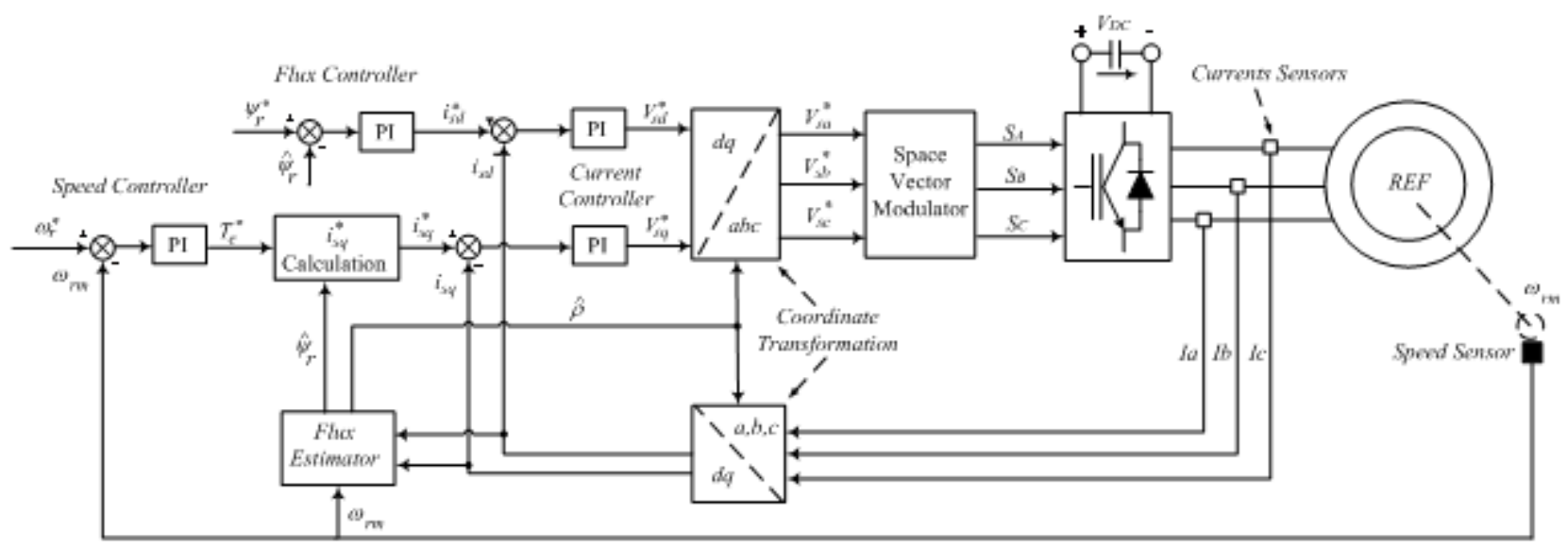

Fig. 4. Block Diagram of Control.

\section{Results of Simulation}

This section aims to analyze through simulation the performance of the system as to the speed control. Two steps of simulations were performed, detailed below. All simulations were performed over time.
The graph in Figure 5 represents the behavior of the power injected into the system by the wind turbine, an approxi-mated value of $1200 \mathrm{~W}$, with variations in step and ramp.

\section{A. Variable Wind Speed and Constant Reference}




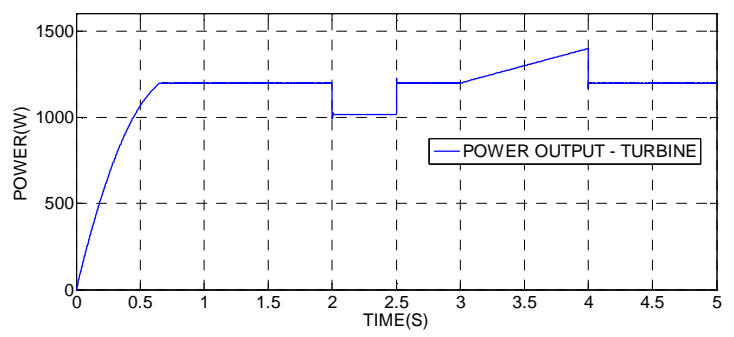

Fig. 5. Wind turbine output power..

Figure 6 is a graph of the final speed of rotation of the synchronous rotor with respect to the reference reaching the expected value of $377 \mathrm{rad} / \mathrm{sec}$. As noted, the system shows sign of zero steady state error, as illustrated by the graph in Figure 7.

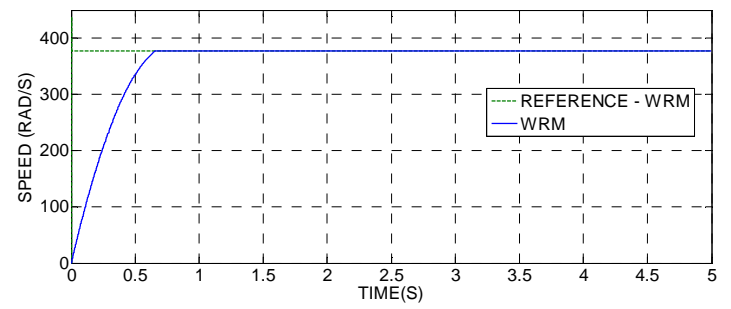

Fig. 6. Wind turbine output power.

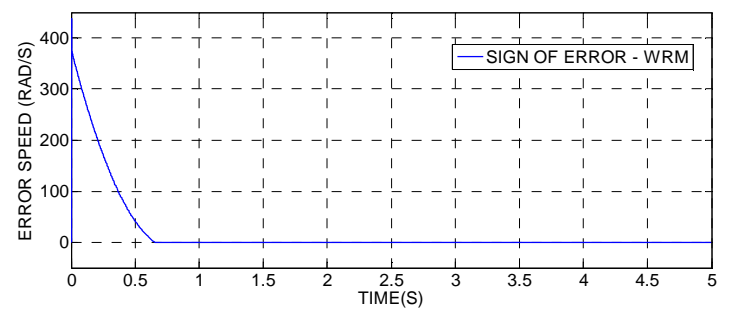

Fig. 7. Error signal Wrm.

\section{B. Wind Speed Constant and Variable Reference}

In this simulation step, was evaluated the system performance to value changes of the reference speed in $+/-5 \%$ over the $377 \mathrm{rad} / \mathrm{s}$ value, maintaining a power input of the turbine on a constant-value equal to $1200 \mathrm{~W}$.

The graphs of Figure 9 and Figure 10 represent the rotational speed of the synchronous rotor with respect to the variation of the reference signal and the variations of the error signal, respectively. It can be seen that once again the system performed well the speed control.

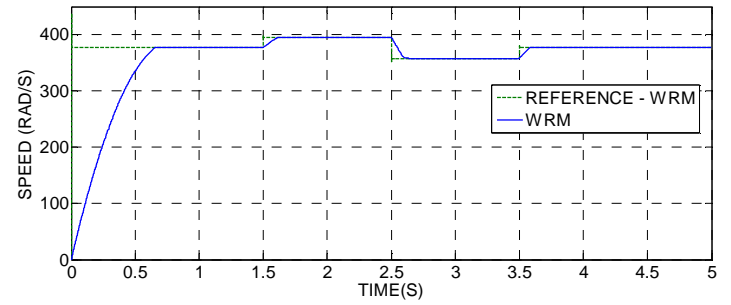

Fig. 8. Wrm Speed and Speed Reference.

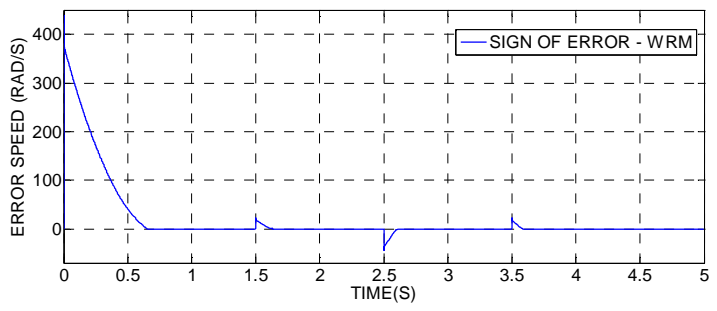

Fig. 9. Error signal Wrm.

\section{Conclusion}

Given the above, it is concluded that the proposed topology presents satisfactory results of simulations. The speed control system was efficient for variations of wind power injected to reference constant speed and also for constant winds with variations of the reference value, with zero steady state error.

The presented system eliminates the use of gearboxes, replaced by EFR, representing a technological breakthrough.

The parameters used in the simulation had been validated and used as the basis for manufacturing the prototype.

\section{References}

[1] World wind energy report, Relatório técnico, World Wind Energy Association, 2014.

[2] Xilu Yi; Heng Nian, "Novel DC grid connection topology and control strategy for DFIG-based wind power generation system," Electrical Machines and Systems (ICEMS), 2013 International Conference on, vol., no., 26-29 Oct. 2013, pp.223228.

[3] Zanchettin, Marcos Guilherme, Análise da inserção de geração eólica com aerogeradores de indução, Dissertação de mestrado, UNIOESTE, 2012.

[4] Ragheb, A.; Ragheb, M., "Wind turbine gearbox technologies," Nuclear \& Renewable Energy Conference (INREC), 2010 1st International, vol., no., March 2010, pp.1,8, 21-24.

[5] Jammal, A.; Rong, Y., "Wind turbine gearbox dynamics," Assembly and Manufacturing (ISAM), 2013 IEEE International Symposium on , vol., no., July 30 2013-Aug. 2 2013, pp.330,333.

[6] Pereira, H.A.; Liu, S.Y.; de Lima Ramos, M.C.; Mendes, V.F.; Silva, S.R., "A comparative analysis of wind turbine technologies in focus on the grid integration," Industry Applications (INDUS-CON), 2010 9th IEEE/IAS International Conference on , vol., no., pp.1,6, 8-10 Nov. 2010.

[7] Daneshi-Far, Z.; Capolino, G. -A; Henao, H., "Modeling and simulation of planetary gearbox effects on a wound rotor induction machine," Industrial Electronics (ISIE), 2012 IEEE International Symposium on, vol., no., 28-31 May 2012, pp.1234,1239.

[8] Xikai Sun; Ming Cheng; Ying Zhu; Longya Xu, "Application of Electrical Variable Transmission in Wind Power Generation Sys-tem," Industry Applications, IEEE Transactions on, vol.49, no.3, May-June 2013, pp.1299,1307 [9] Garcia-Hernandez, R.; Garduno-Ramirez, R., "Modeling and Control of a Wind Turbine Synchronous Generator," Electronics, Robotics and Automotive Mechanics Conference (CERMA), 2011 IEEE, vol., no., 15-18 Nov. 2011, pp.222,227. [10] Liu, Silas Yunghwa, Controle direto de potência em gerador de indução duplamente alimentado, Dissertação de mestrado, UFMG, 2011. 
[11] Shuxi Liu; Shan Li; Huihui Xiao, "Vector Control System of Induction Machine Supplied by Three-Level Inverter Based on a Fast SVPWM Algorithm," Intelligent System Design and Engineering Application (ISDEA), 2010 International Conference on , vol.2, no., 13-14 Oct. 2010, pp.810,813

[12] Jacobina, C. B.; Lima, Antonio Marcus Nogueira. Estratégias de Controle Para Sistemas de Acionamento Com Máquina Assín-crona. SBA. Sociedade Brasileira de Automática, São Paulo, v. 7, n.1, p. 15-28, 1996. 